\title{
Expression, function, and regulation of the hairy segmentation protein in the Drosophila embryo
}

\author{
Sean B. Carroll, ${ }^{1}$ Allen Laughon, ${ }^{2}$ and Bruce S. Thalley ${ }^{1}$ \\ ${ }^{1}$ Laboratory of Molecular Biology, University of Wisconsin, Madison, Wisconsin 53706 USA; ${ }^{2}$ Departments of Genetics and \\ Medical Genetics, University of Wisconsin, Madison, Wisconsin 53706 USA
}

The Drosophila pair-rule segmentation gene, hairy, is required for the proper development of alternate embryonic segment primordia and the normal spatial expression of another pair-rule gene, fushi tarazu (ftz). We demonstrate that the product of the hairy gene is localized to the nuclei of cells in eight distinct regions of the early embryo. The major stripes of protein accumulation comprise the posterior half and the adjacent anterior portion of alternate segment primordia; the hairy pattern overlaps transiently with ftz expression in a narrow band of cells. Unlike other pair-rule products that have been studied, hairy is not expressed in the embryonic nervous system. The spatial distribution of the nuclear hairy protein and the pattern of $f t z$ expression in embryos lacking hairy function suggests that hairy plays a direct role in repressing ftz gene expression. The pattern of hairy expression in gap gene mutants that affect $f t z$ expression indicates that the gap genes largely act indirectly upon $\mathrm{ftz}$ through their effects on hairy.

[Key Words: Segmentation; hairy; gene regulation; embryogenesis; pattern formation]

Received March 9, 1988; revised version accepted May 9, 1988.

The segmentation of the Drosophila embryo depends upon the proper action of a number of genes expressed during oogenesis and the early development of the zygote. Systematic screens for zygotically required loci have identified approximately 20 genes that establish the proper number and orientation of body segments (Nüsslein-Volhard and Wieschaus 1980; Jürgens el al. 1984; Nüsslein-Volhard et al. 1984; Wieschaus et al. 1984). At least three classes of segmentation gene activity may be distinguished, based upon the pattern of segment defects observed in the late embryo (NüssleinVolhard and Wieschaus 1980; for review, see Akam 1987; Scott and Carroll 1987). The gap genes affect the development of large, mostly contiguous blocks of segments; the pair-rule genes affect the development of segmental pattern at double-segment intervals; and the segment polarity genes control the development of pattern elements within each segment. Many of the segmentation genes have now been cloned and characterized at the molecular level.

One well-studied segmentation gene is the fushi tarazu $(f t z)$ pair-rule locus. The $f t z$ gene is transcribed in seven transverse stripes encircling the cellular blastoderm-stage embryo (Hafen et al. 1984) that correspond to the positions of the embryonic segment primordia affected in $f t z$ mutants (Martinez-Arias and Lawrence 1985). The $f t z$ protein accumulates within the nuclei of blastoderm cells and in a subset of cells within the developing nervous system (Carroll and Scott 1985). The striking and complex pattern of $f t z$ expression has prompted the analysis of the factors that are involved in the regulation of the $f t z$ gene. To identify putative transacting regulators of $f t z$, the pattern of $f t z$ expression in most known zygotic segmentation mutants was examined (Carroll and Scott 1986). All four gap genes and three of seven pair-rule genes affected the establishment of the normal striped pattern. Although these studies established the formal interactions between segmentation genes and $f t z$, nothing could be discerned about the mechanisms of gene interaction.

Of the known zygotic regulators of $f t z$, one gene in particular, the hairy pair-rule locus, appears to exhibit a negative regulatory effect on $\mathrm{ftz}$ (Carroll and Scott 1986; Howard and Ingham 1986). In embryos lacking hairy function, it has been shown that $f t z$ expression expands to include most cells in the interstripe region (Carroll and Scott 1986; Howard and Ingham 1986). The hairy gene has been cloned (Holmgren 1984; Ish-Horowicz et al. 1985) and the expression of its RNA transcripts has been analyzed (Ingham et al. 1985). The hairy transcripts accumulate in seven transverse stripes and in a large anterior dorsal region of the cellular blastoderm-stage embryo; the transverse hairy stripes are out of phase with and partly overlap the $f t z$ stripes at blastoderm.

We describe the pattern of expression, subcellular localization, and spatial regulation of the hairy protein. A hairy cDNA clone was expressed in bacteria as a fusion protein with $\beta$-galactosidase, and antibodies were raised 
and purified that reacted specifically with the hairy protein. Immunostaining of whole-mount embryos revealed that hairy is found within cell nuclei and is expressed in blastoderm-stage cells and in a few cells surrounding part of the tracheal system formed later in embryogenesis. By comparing $f t z$ and hairy expression in wildtype and mutant embryos, our studies strongly suggest that hairy is a direct regulator of $f t z$-gene expression and that three other previously identified potential regulators of $f t z$ act primarily indirectly upon $f t z$ through the hairy gene. Because, unlike most characterized Drosophila regulatory genes (Scott and Carroll 1987), hairy does not contain any recognizable nucleic acid binding domains (C. Rushlow, pers. comm.), it is of great interest to learn how it regulates expression of $f t z$.

\section{Results and discussion}

Antibodies to hairy reveal a nuclear distribution of the protein in two different spatial patterns during embryogenesis

To study the expression and function of the hairy gene product, we have prepared antibodies to a lacZ-hairy fusion protein. Antibodies were raised in rabbits against the 335-amino-acid full-length hairy protein (C. Rushlow, pers. comm.|, and hairy-specific antibody was purified as described previously (Carroll and Laughon 1987). These antibodies were used to stain fixed wholemount embryos (Carroll and Scott 1985). Cell labeling was visualized either directly with the chromogenic horseradish peroxidase substrate diaminobenzidine (DAB), or indirectly by observing the quenched pattern of the DNA-binding fluorochrome 4,6,-diamidino-2phenyl-indole (DAPI) caused by deposition of oxidized DAB, a method recently developed by Tim Karr (T. Karr and T. Kornberg, in prep.)]. This latter method, termed filtered fluorescence imaging (FFI), is more sensitive than previous immunofluorescence methods and makes it possible to visualize both labeled and unlabeled cells.

As is the case for hairy RNA transcripts (Ingham et al. 1985), the hairy protein accumulates in eight discrete regions of the embryo (Fig. la). At the cellular blastoderm stage of embryogenesis, there are seven transverse stripes of hairy protein encircling the embryo and one dorsal patch of hairy expression at the extreme anterior. The most anterior hairy stripe forms at $\sim 75 \%$ egg length (measured from the posterior), which is anterior to the position of the cephalic furrow established during gastrulation. The seven stripes are not of equal size and intensity. The first stripe is significantly wider than the others; this is most pronounced on the ventral surface of the embryo where the stripe includes five to seven nuclei, on the average. The fourth stripe is consistently weaker than the others in all dimensions. On average, on the lateral sides of the embryo the hairy stripes are about three cells in width and are separated by four to five unlabeled cells / these unlabeled cells can be seen in Fig. $1 \mathrm{~b}$ most clearly as white, unquenched DAPI-stained nuclei). The dorsal patch of staining extends along $\sim 20 \%$ of the dorsal surface of the embryo $(\sim 12-14$ cells in diam.) and comprises about 150 cells in total.

The hairy labeling is concentrated within the nuclei of cells. At high magnification, the staining appears punctate and resembles the pattern of staining exhibited with chromatin-binding counterstains (Fig. lc). Although most of the cell volume at this stage of embryogenesis is filled by the nucleus, we do not detect hairy staining outside of the nucleus. In contrast, cytoplasmic antigens, such as Escherichia coli $\beta$-galactosidase expressed under $f t z$ control (Hiromi et al. 1985), exhibit no staining within the nucleus (data not shown). We conclude that the hairy protein is largely confined to the

Figure 1. Expression of the hairy protein in the Drosophila embryo. Affinity purified rabbit antibody to the hairy protein was used to localize hairy antigen in formaldehyde-fixed, devitellinized whole-mount embryos. (a) Bright-field image of cellular blastoderm embryo exhibiting eight regions of hairy expression. Anterior is to the left, the ventral surface at the bottom. $(b)$ DAPI fluorescent image of the same stained embryo in $(a)$, showing pattern of unlabeled nuclei (bright dots) on background of darkly stained hairy-containing nuclei. The deposition of DAB quenches the fluorescence of DAPI (T. Karr and T. Kornberg, in prep.). (c) High-magnification, bright-field view of stripe of hairy expression. The labeling appears punctate and is nuclear; the darker areas (arrows) conform to the pattern of chromatin distribution. (d) Later pattern of hairy expression at the germ-band-extension stage of embryogenesis. Ten tracheal pits extending from parasegments (PS) 4-13 are clearly labeled,

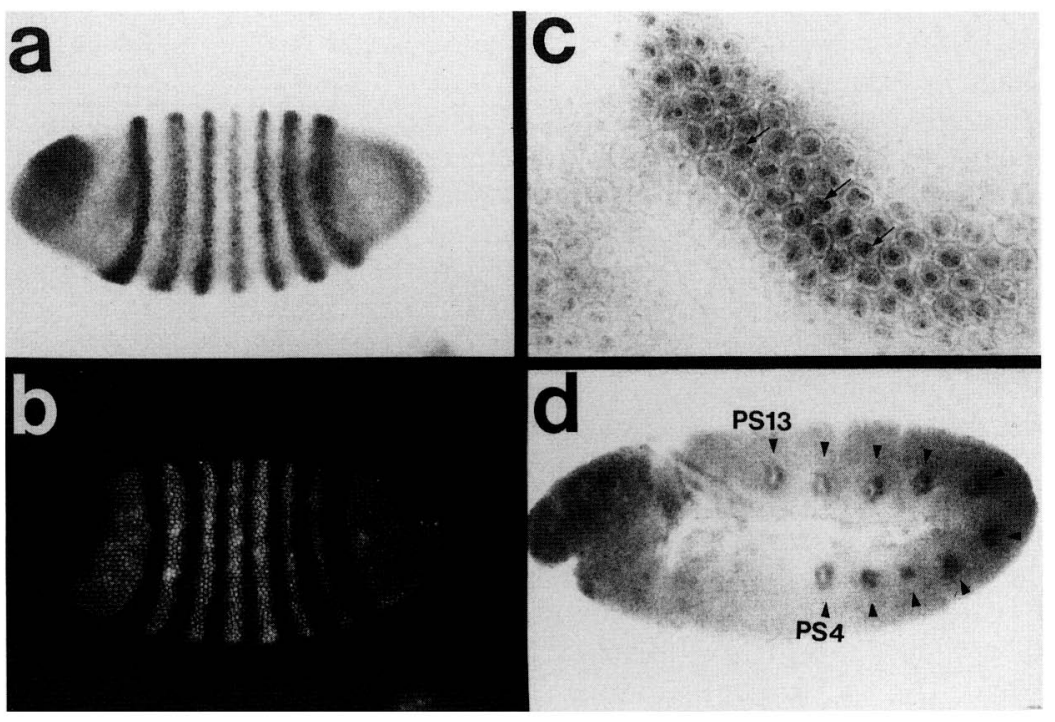
staining appears to be confined to six to eight cells around each pit. 
nucleus, consistent with its genetic regulatory function.

The hairy protein pattern decays rapidly during gastrulation and germ-band extension. The hairy protein is no longer detectable in the stripes shortly after the germ band begins extension. In contrast, the $f t z$ and evenskipped (eve) pair-rule proteins are still detectable at this stage (Carroll and Scott 1985; Frasch et al. 1987). The hairy protein is expressed again later in embryogenesis in a group of cells surrounding each of 10 pairs of tracheal pits in the germ-band-extended embryo (Fig. 1d). Only the tracheal pits extending from parasegments 4 to 13 express hairy. This transient pattern was not expected from morphological studies of hairy mutants; it is not known what function hairy has in the six to eight cells stained within each pit. Neither blastoderm nor tracheal pit staining is observed in homozygous hairy ${ }^{7 H 94}$ embryos, indicating that all of the observed staining is due to the bona fide hairy product (data not shown). Multiple transcripts of the hairy gene have been documented: It is possible that the tracheal pit expression is under different regulatory controls than the blastoderm expression (Ish-Horowicz et al. 1985). Unlike $\mathrm{ftz}$ and eve, hairy is not detected within the embryonic ventral nervous system (data not shown). Perhaps the expression patterns of the pair-rule genes in the nervous system represent different functions and regulatory controls of these genes than that which occurs in the ectoderm.

\section{The spatial relationship of hairy expression to other} pair-rule genes

Using antibodies to the eve (Frasch et al. 1987), ftz (Carroll and Scott 1985), and hairy products, we have used double labeling of embryos to determine more precisely the spatial relationship between hairy and the other pair-rule gene patterns. The $f t z$, eve, and hairy products all reach their maximum level of accumulation at the completion of cellularization of the blastoderm embryo (Fig. 2a-c). At this moment, each transverse stripe of pair-rule expression is generally narrower than the interstripes. We emphasize that these expression patterns are observed near the completion of cellularization, and the initiation of gastrulation. There are different transient spatial protein patterns during very early cellularization, but they do not represent the final high-level accumulation patterns. At these earlier times, $f t z$, eve, and hairy all exhibit transient patterns, where different protein stripes vary in width and intensity / $T$. Karr and T. Kornberg, in prep.; S. Carroll, unpubl.). These transition patterns are striking and could reflect the interactions between segmentation genes in establishing the final patterns. The patterns we detail below demonstrate the outcome of these interactions and help to reveal the regulatory relationships between these three pair-rule genes.

The relatively low level of hairy expression made double immunofluorescence localization techniques impossible. Instead, we have visualized protein products simultaneously, using immunoenzymatic techniques and the FFI method to produce sharp images of each antigen's pattern within embryos (T. Karr and T. Kornberg, in prep.). Each protein's pattern appears as a gray-toblack quenched zone against a background of bright, unquenched nuclei. We are able to map precisely the position of cells containing one, none, or both of the products examined in each embryo. By double-labeling embryos with the appropriate concentrations of three different pair-wise combinations of hairy, $f t z$, and eve antibodies, we can determine their relative spatial patterns. As hairy protein reaches its maximum level, it can be seen that there are cells that express both hairy and $f t z$ (Fig. 2d). This has also been observed for their respective transcripts (Ingham et al. 1985). These cells are the most posterior cells within a portion of each $f t z$ stripe. The overlap is more pronounced at ventrolateral positions (Fig. 2e, arrows) and is very transitory: By the time gastrulation is evident, hairy expression abuts but no longer overlaps $f t z$ (Fig. 2f). Based on examination of a large sample of double-labeled cellular blastoderm- and early gastrulation-stage embryos, we conclude that accumulation of hairy within the more posterior ftz-containing cells leads quickly to repression of $f t z$ expression and the observed narrowing of the $f t z$ stripes (Carroll and Scott 1985).

The periodicity of $f t z$ and eve can be used to extend the above observations and establish a more precise map of pair-rule protein spatial patterns. Double-labeling with $f t z$ and eve antibodies shows that at the end of cellularization, the eve and $f t z$ domains are often, but not always, separated by stripes approximately one cell wide (Fig. 2g, h); these gaps become more pronounced as gastrulation proceeds (Fig. 2i). This is largely in agreement with previous studies showing that eve defined the boundaries of odd-numbered parasegments, whereas $\mathrm{ftz}$ established the even-numbered parasegments (Frasch and Levine 1987; Lawrence et al. 1987).

Although hairy expression leads to repression of $f t z$, coexpression of hairy and eve is permitted. The hairy and eve protein patterns overlap extensively but are out of phase (Fig. 2j). At ventrolateral positions, hairy expression extends about three cells anterior to the first (most anterior) eve stripe, about two cells anterior to the second eve stripe, about one cell anterior to the third eve stripe, and appears to be virtually coincident with the fourth eve stripe, (Fig. 2k, arrow). Thus, although hairy exhibits a periodic pattern, it is out of phase with both the $f t z$ and eve periodicity, and each hairy stripe varies subtly in intensity, width, and distance from adjacent stripes.

By comparing the above double- and single-labeling patterns of many individual staged embryos, the spatial relationships between all of these pair-rule products can be determined. We summarize our assessment of the relative spatial expression of the hairy, $f t z$, and eve proteins over a portion of the cellular blastoderm- and early gastrulation-stage embryo in Figure 3. It should be emphasized that earlier and later patterns exist that differ from the map in Figure 3. However, we have chosen to focus on the patterns as the embryo completes cellularization 


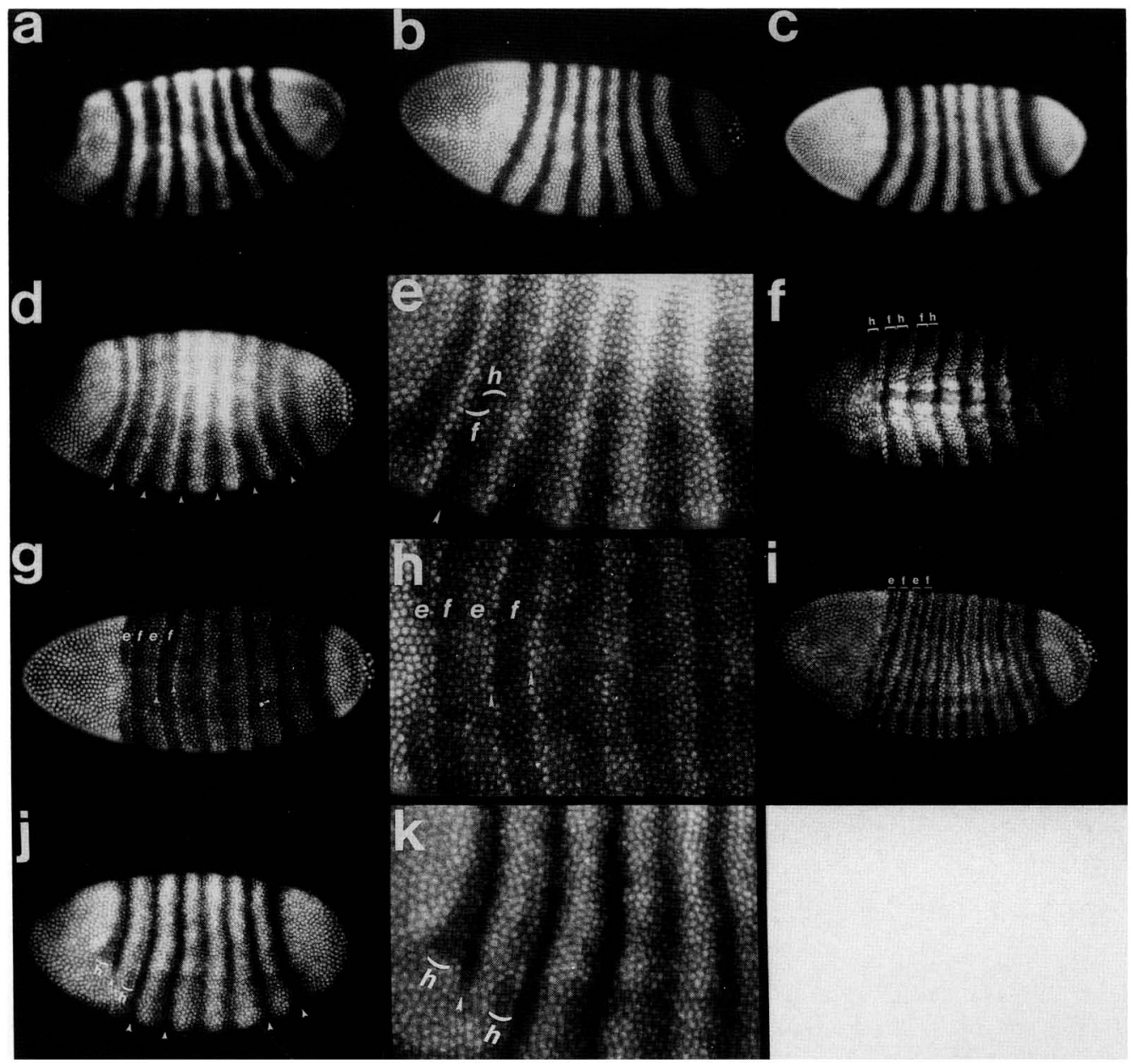

Figure 2. The relative spatial patterns of the hairy, $f t z$, and $e v e$ pair-rule proteins. Embryos were stained with affinity purified rabbit antibodies to either the hairy, eve (courtesy of $M$. Frasch and $M$. Levine), or $f t z$ proteins, singly or in pair-wise combinations and their patterns revealed by counterstaining with DAPI (T. Karr and T. Kornberg, in prep.). Anterior is to the left, ventral at the bottom of each image. $(a)$ The wild-type hairy pattern. The seven transverse black stripes are separated by six unquenched white interstripes. $(b)$ The wild-type $f t z$ pattern. The seven quenched (black) stripes form around six unquenched (white) interstripes [hairy expression extends over most, but not all, cells within the interstripes (see $d$ below)]. (c) The wild-type eve pattern. The seven quenched stripes are out of phase with the $f t z$ stripes, and form one segment anterior to each $f t z$ stripe (see $g$ below) and partially overlap the hairy stripes (see $j$ below). $(d, e)$ The combined hairy and $f t z$ protein patterns at low $(d)$ and high $(e)$ magnification. Nine zones of partial quenching are detectable, eight of which are transverse bands. The most anterior transverse band is made up of hairy protein alone. A band, about six cells wide, is detected posterior to a gap of about two to three cells. There are three levels of staining observed within this quenched zone. The staining is due to ftz-expressing cells on the anterior edge (brackets in $e$ ), it is due to hairy-expressing cells on the posterior edge (brackets in $e$ ), and there is a narrow discontinuous band of strongly quenched cells that express both hairy and ftz at the interface (arrowheads in $d$ and $e$ ). This pattern is reiterated down the anteroposterior axis of the embryo six times until the most posterior band of $f t z$ expression is reached. $(f)$ Ventral view of an embryo showing the relationship between hairy and $f t z$ expression at gastrulation. The weak hairy $(\mathrm{h})$ stripes abut the stronger $f t z(\mathrm{f})$ stripes but do not exhibit any detectable overlap at this stage. $(g)$ The combined $f t z$ and $e v e$ patterns establish 14 dark zones of quenching, which are interrupted in certain places by narrow strips of relatively unquenched bright nuclei (arrowheads). From the anterior (left), all gray zones are $e v e$ (e) domains, and all dark zones are $f t z$ (f) domains. $(h)$ High-magnification view of a portion of the embryo shown in $(g)$. The $f t z(f)$ and $e v e$ (e) zones are indicated. The arrowheads indicate the position of the same unquenched nuclei shown in $g$. (i) The relationship between $f t z$ and $e v e$ at gastrulation. The $f t z$ and $e v e$ stripes are narrower, and unquenched zones now separate each eve and $f t z$ domain, as opposed to the slightly earlier stage shown in $g ;(\mathrm{f}) f t z$ zones; (e) eve zones. (i) The combined hairy and eve patterns. Eight zones of quenching are created by the combined probes, seven of which are transverse bands. Each band is made up of an eve stripe that is partially overlapped by a stripe of hairy protein. At the anterior the first hairy stripe extends two to three nuclei anterior (bracket, h) to the first eve stripe (arrowhead). Although we can deduce that hairy overlaps eve, the very high relative level of eve expression precludes the detection of distinct overlap zones. The weakly quenched hairy-containing cells can be observed anterior to the first three eve stripes but extend anterior to them to different degrees. The most anterior hairy stripe does not extend completely ventrally; this is observed in about $10 \%$ of wild-type embryos. $(k)$ High-magnification view of portion of the embryo shown in $j$. The brackets indicate the position of cells containing hairy only; the arrowhead indicates the position of an eve stripe that overlaps hairy. 


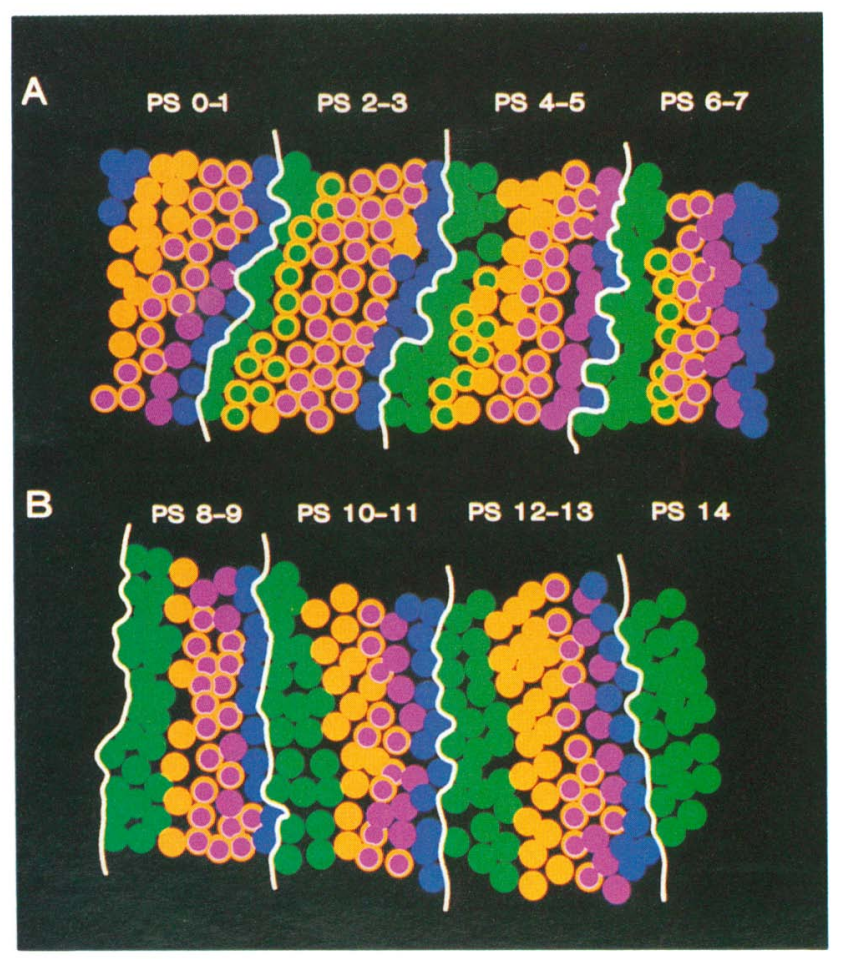

Figure 3. Summary of relative spatial patterns of hairy, $f t z$, and $e v e$ at the completion of cellularization. From the inspection of embryos comparable or identical to those illustrated in Figure 2, the relative spatial patterns of hairy (orange), eve (purple), and $f t z$ (green) expression are plotted. A schematic representation of the anterior ventrolateral portion of a cellular blastoderm-stage embryo $(A \mid$ and the posterior ventrolateral portion of a gastrulating embryo $(B)$ depicts the expression of the three proteins over the cells (circles) from a few segment primordia. The different parasegments (PS) represented are indicated. The hairy and $f t z$ patterns have been traced directly from photomicrographs and the eve pattern has been derived from analysis of several multiply labeled embryos. Cells that express none of the three proteins are denoted by blue circles; overlaps between two protein patterns are indicated by the double coloring of circles.

and begins gastrulation, because it is the moment of high-level accumulation of each protein in its most complete pattern and best reflects the regulatory interactions believed to occur between these genes. The most pertinent observations schematized in Figure 3 are that (1) hairy and $f t z$ proteins overlap transiently in the posterior-most cells of each $f t z$ stripe; (2) hairy and eve proteins coexist at high levels in the anterior-most cells of each eve stripe; (3) these relationships evolve rapidly as the $f t z$ and eve stripes narrow during cellularization and gastrulation; and (4) the exact spatial phasing of each stripe, especially the hairy pattern, is not identical within each double-segment unit. This last point was somewhat unexpected as we and others have treated each double-segment primordia and stripe of pair-rule gene expression as being largely equivalent. The subtle differences in pair-rule stripe widths and overlaps that we observed as the embryo completes cellularization probably involve at least three processes. First, the hairy stripes appear asynchronously during cellularization; the regional differences in protein accumulation probably reflect gap gene influences that differ greatly between segment primordia. Second, the eve and ftz patterns narrow as cells enter the ventral furrow and transverse folds begin to form, and the density of cells in the ectoderm changes, so some of these phase changes may reflect cell movements. And, finally, the decay of individual protein stripes may occur at different rates depending upon the extent of active repression occurring within individual cells and the rate of protein turnover. The mechanism for turning off pair-rule gene expression is not known; it is likely that it is also a significant factor in the phase shifts in gene expression patterns in different segment primordia.

\section{Regulation of the $\mathrm{ftz}$ gene by the hairy protein}

It has been shown previously that the zygotic loss of hairy-gene function leads to an expansion in the $\mathrm{ftz}$ expression domain (Carroll and Scott 1986; Howard and Ingham 1986). We can compare how ftz expands in a hairy ${ }^{-}$embryo with the normal domains of hairy and $f t z$. In wild-type embryos, the sum of hairy and $f t z$ expression still leaves seven narrow bands of unlabeled cells (Fig. 4a). However, as shown in Figure 4b, in hairy mutant embryos that fail to express detectable hairy protein (not shown), ftz expression expands into broad

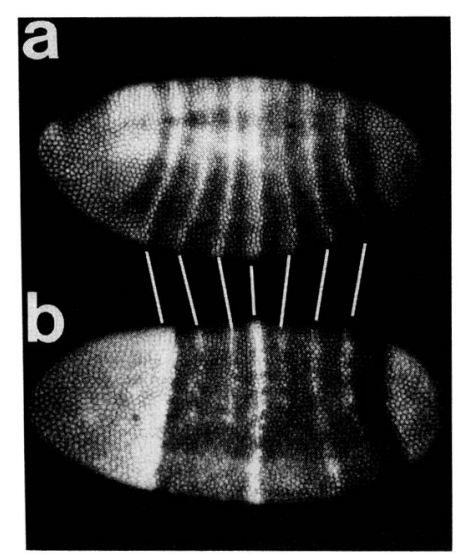

Figure 4. $f t z$ expression in hairy mutants extends into cells not normally accumulating hairy to high levels. Embryos were stained with antibodies, as described in Figure 1. (a) Wild-type embryo at the cellular blastoderm stage doubly labeled with $f t z$ and hairy antibody. Note the seven narrow bands of unquenched nuclei (lines) separating each broader domain; these cells express neither $f t z$ nor hairy protein. $(b)$ The expression of $f t z$ in an embryo at the same stage as in $a$, but this animal is homozygous for the strong hairy ${ }^{794}$ allele. $f t z$ expression expands into broad largely continuous domains that include the normal ftz-expressing cells, cells normally expressing hairy, and cells normally at the unlabeled boundaries indicated in $a$ (lines). We analyzed 25 homozygous hairy ${ }^{794}$ embryos, and they all exhibited the broad $f t z$ pattern. 
domains that are larger than the domains defined by the sum of hairy and $f t z$ expression in wild-type embryos. These results support the view that hairy is normally required in cells that do not accumulate it to high levels (Howard and Ingham 1986). We have observed transient early patterns of hairy protein accumulation in cells that do not belong to any of the final cellular blastoderm hairy stripes (S. Carroll, unpubl.), perhaps these cells require hairy transiently for normal $f t z$ regulation. Thus, unstable intermediate hairy expression patterns, rather than cell nonautonomy (Howard and Ingham 1986), may explain the behavior of $f t z$ expression in hairy mutant embryos.

The correlation between hairy and ftz expression in gap mutants

The zygotically required gap genes Krüppel $(K r)$, hunchback (hb), and knirps (kni) affect the development of large regions of the embryo. Loss of each of their functions leads to deletions of continuous blocks of segments (Nüsslein-Volhard and Wieschaus 1980) and improper expression of pair-rule genes (Carroll and Scott 1986; Ingham et al. 1986; Frasch and Levine 1987). It is not known at what level gap genes influence pair-rule gene expression, which interactions are direct or indirect, or how the patterns of gap gene expression are related to the periodic pair-rule patterns. One step toward analyzing gap gene/pair-rule gene interactions is to understand how each gene is affected by the absence of gap gene function. In a previous study, it was shown in $K r$ mutant embryos that hairy and $f t z$ transcript patterns assume complementary patterns, indicating that the effect of $K r$ upon $f t z$ may be mediated indirectly through hairy (Ingham et al. 1986).
The $f t z$ gene is expressed abnormally in embryos lacking $\mathrm{Kr}^{+}$(Fig. 5a), kni+ (Fig. 5c), or $\mathrm{hb}^{+}$(Fig. 5e) functions. To determine whether any of these effects could be mediated through the regulatory action of the hairy gene, we examined hairy expression in these same mutants (Fig. 5b,d,f). In the $\mathrm{Kr}^{-}$and $\mathrm{kni}^{-}$embryos, the $\mathrm{ftz}$ patterns are complementary to the hairy patterns (Fig. $5 \mathrm{a}-\mathrm{d}$, arrows indicate complementary regions). Because hairy regulates $f t z$, but $f t z$ has no influence on hairy (Howard and Ingham 1986), it is evident that the effects of these two mutants on hairy and hairy's negative control of $f t z$ may largely explain the observed $f t z$ patterns. However, in the $h b^{-}$embryo, the $f t z$ and hairy patterns are not entirely complementary (Fig. $5 \mathrm{e}$, f). In the posterior region of the $h b^{-}$embryo, hairy and $f t z$ expression expand into broader domains (Fig. $5 \mathrm{e}, \mathrm{f}$, brackets). The seventh hairy stripe overlaps the fused sixth and seventh $f t z$ stripes. Normally, we would expect that, in its role as a negative regulator of $f t z$, hairy would prevail and repress $f t z$ expression over this region. This is not the case in $h b^{-}$embryos; the broad posterior $f t z$ stripe persists through gastrulation. It appears then that $h b$ must be controlling more than just hairy to explain its effects on $f t z$. $h b$ could act directly on $f t z$ or control yet another gene that directly regulates $f t z$. It is known that runt and eve also regulate $f t z$ (Carroll and Scott 1986) and that they interact with each other and hairy (Frasch and Levine 1987; S. Carroll, unpubl.). The complete elucidation of the early segmentation gene network will require detailed study of these subtle and frequently bilateral interactions. Clearly, further investigation into the mechanism of regulation of the hairy gene by the gap genes and the other pair-rule loci is intimately tied to understanding how $f t z$ comes to be expressed in stripes.

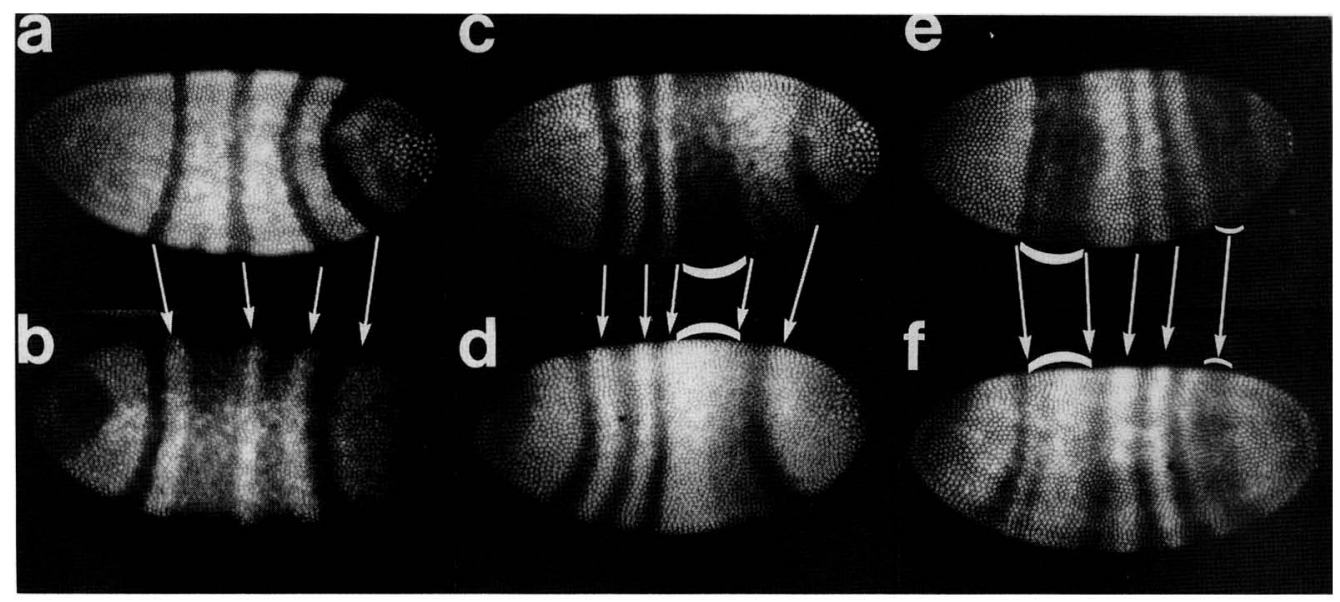

Figure 5. hairy expression in gap mutants is complementary to that of its regulatory target, the ftz gene. Embryos homozygous for strong mutations at the $K r, k n i$, and $h b$ gap loci were stained with either $f t z(a, c, e)$ or hairy $(b, d, f)$ antibody. (For the wild-type patterns, see Fig. 2a,b.) The correlations between each spatial pattern were confirmed by double labeling mutant embryos with hairy and $f t z$ antibodies (not shown). $(a, b) f t z$ and hairy patterns in $K r^{1}$ embryos. The arrows indicate how regions that express $f t z$ do not express hairy. $(c, d) f t z$ and hairy patterns in $k n i^{I l \in 72}$ embryos. The arrows indicate the complementarity between the patterns. (e,f) $f t z$ and hairy patterns in $h b^{-}$embryos. The patterns are largely, but not entirely, complementary. Posteriorly it appears that ftz and hairy overlap over a significant length of the embryo, (see posterior bracket). The ftz pattern is unexpectedly stable and is not fully repressed by the expanded hairy stripe. 


\section{The function of the nuclear hairy protein}

The nuclear localization of hairy, its spatial relationship to $f t z$ expression, and the pattern of $f t z$ expression in hairy and gap mutant embryos all suggest a regulatory role for hairy in the control of $f t z$ gene expression. In addition, it has been shown recently that induction of hairy expression throughout the embryo utilizing a heat shock promoter-hairy gene construct results in the elimination of $f t z$ expression (Ish-Horowicz and Pinchin 1987). These observations are all consistent with, but do not yet prove, a direct function for hairy in regulating $f t z$ gene expression.

The hairy protein could interact with ftz DNA, RNA, or protein. It is doubtful that hairy interacts solely at the RNA level because it has been shown that the turnover of $f t z$ RNA takes place at equivalent rates across the embryo, in both the hairy-containing interstripes and in the ftz stripes lacking hairy expression (Edgar et al. 1986). hairy could indeed be a transcriptional regulator, but it is important to note that unlike $f t z$, eve, and a variety of other Drosophila genes, hairy does not contain a homeo box (for review, see Scott and Carroll 1987), nor does it contain a nucleic acid-binding zinc finger structure present in the Krüppel (Rosenberg et al. 1986) and $h b$ (Tautz et al. 1987) gap genes (C. Rushlow, pers. comm.). If hairy acts via binding to nucleic acid, it utilizes a different mechanism than that of other characterized Drosophila regulatory genes. All data are also consistent with a potential function for hairy in inactivation of the $\mathrm{ftz}$ protein. The full-level activation of the $\mathrm{ftz}$ gene involves an auto-feedback enhancement by the $f t z$ protein (Hiromi and Gehring 1987). Inactivation by hairy of this autocatalytic mechanism at the $f t z$ protein level could be one way to regulate the pattern of $f t z$ expression. In addition, it has been shown that hairy may be a positive regulator of eve (Frasch and Levine 1987). The determination of the biochemical function of the hairy protein and its potentially opposite effects on different pair-rule genes await in vitro analysis of these various possibilities with purified recombinant protein.

\section{Methods}

\section{Antibodies}

Rabbit antibodies to the eve protein were generously provided by $M$. Frasch and $M$. Levine. The $f t z$ and hairy antibodies were produced as described elsewhere (Carroll and Scott 1985; Carroll and Laughon 1987).

\section{Immunolabeling}

Embryos were permeabilized, fixed, devitellinized, and prepared for staining as described elsewhere (Carroll and Scott 1985).

Primary antibodies were incubated at $0.1-1.5 \mu \mathrm{g} / \mathrm{ml}$ in phosphate-buffered saline containing $10 \mathrm{mg} / \mathrm{ml}$ bovine serum albumin (BSA) and $0.1 \%$ Triton $\mathrm{X}-100$ ( $\mathrm{vol} / \mathrm{vol})$. The antibodies were detected by incubation with biotinylated goat anti-rabbit IgG followed by streptavidin-horseradish peroxidase conjugate and development with diaminobenzidine in the presence of $002 \% \mathrm{H}_{2} \mathrm{O}_{2}$ and $0.03 \% \mathrm{Co}^{2+}$ and $\mathrm{Ni}^{2+}$. Embryos were then counterstained with DAPI at $10 \mu \mathrm{g} / \mathrm{ml}$ for $30 \mathrm{~min}$ and mounted for viewing in $50 \mathrm{~mm}$ Tris $(\mathrm{pH} 8.8)$ containing $10 \%$ glycerol (vol/vol).

Bright-field photography was done with Kodak Technical Pan film, and fluorescence photography was done with Kodak Tri-X film.

Double labeling with rabbit antibodies was achieved by careful titration of the relative concentrations of each reagent.

Detailed protocols are available upon request.

\section{Acknowledgments}

We thank Tim Karr for sharing detailed information on his development of the FFI method long before publication. We are grateful to Chris Rushlow for generously providing a full-length characterized and sequenced hairy cDNA clone, and to Manfred Frasch and Mike Levine for their potent eve antibody. We thank Bill Howell for technical assistance, Jeff Granby (Eberhardt Instruments) for many helpful pointers on improving our microscopic images, Mike Hoffman and Phil Anderson for comments on the manuscript, Leslie Compere and Steve Limbach for work on the illustrations, and Ms. Pat Hanson for secretarial assistance. An early portion of this work was supported by a National Institutes of Health $(\mathrm{NIH})$ grant to Matthew Scott while S.C. and A.L. were at the University of Colorado (Boulder). This work has been substantially supported by seed funds from the University of Wisconsin to S.B.C. and A.L. and an American Cancer Society Institutional grant (IN-35-20-2) to S.B.C.

\section{References}

Akam, M. 1987. The molecular basis for metameric pattern in the Drosophila embryo. Development 101: 1-22.

Carroll, S.B. and A. Laughon. 1987. Production and purification of polyclonal antibodies to the foreign segment of $\beta$-galactosidase fusion proteins. In DNA cloning: A practical approach (ed. D. Glover), vol. 3, pp. 89-111. IRL Press, Oxford.

Carroll, S.B. and M.P. Scott. 1985. Localization of the fushi tarazu protein during Drosophila embryogenesis. Cell 43: 47-57.

-1986. Zygotically active genes that affect the spatial expression of the fushi tarazu segmentation gene during early Drosophila embryogenesis. Cell 45: 113-126.

Edgar, B.A., M.P. Weir, G. Schubiger, and T. Kornberg. 1986. Repression and turnover pattern of fushi tarazu RNA in the early Drosophila embryo. Cell 47: 747-754.

Frasch, M. and M. Levine. 1987. Complementary patterns of even-skipped and fushi tarazu expression involve their differential regulation by a common set of segmentation genes in Drosophila. Genes Dev. 1: 981-995.

Frasch, M., T. Hoey, C. Rushlow, H. Doyle, and M. Levine. 1987. Characterization and localization of the even-skipped protein of Drosophila. EMBO I. 6: 749-759.

Hafen, E., A. Kuroiwa, and W.J. Gehring. 1984. Spatial distribution of transcripts from the segmentation gene fushi tarazu during Drosophila embryonic development. Cell 37: 833841.

Hiromi, Y. and W.J. Gehring. 1987. Regulation and function of the Drosophila segmentation gene fushi tarazu. Cell 50: $963-974$.

Hiromi, Y., A. Kuroiwa, and W.J. Gehring. 1985. Control elements of the Drosophila segmentation gene fushi tarazu. Cell 43: 603-613.

Holmgren, R. 1984. Cloning sequences from the hairy gene of Drosophila. EMBO J. 3: 569-573. 
Carroll et al.

Howard, K. and P. Ingham. 1986. Regulatory interactions between the segmentation genes fushi tarazu, hairy, and engrailed in the Drosophila blastoderm. Cell 44: 949-957.

Ingham, P.W., K.R. Howard, and D. Ish-Horowicz. 1985. Transcription pattern of the Drosophila segmentation gene hairy. Nature 318: 439-445.

Ingham, P.W., D. Ish-Horowicz, and K.R. Howard. 1986. Correlative changes in homeotic and segmentation gene expression in Krüppel embryos of Drosophila. EMBO /. 5: 16591665.

Ish-Horowicz, D. and S.M. Pinchin. 1987. Pattern abnormalities induced by ectopic expression of the Drosophila gene hairy are associated with repression of $f t z$ transcription. Cell 51: 405-415.

Ish-Horowicz, D., K.R. Howard, S.M. Pinchin, and P.W. Ingham. 1985. Molecular and genetic analysis of the hairy locus in Drosophila. Cold Spring Harbor Symp. Quant. Biol. 50: $135-144$.

Jürgens, G., E. Wieschaus, C. Nüsslein-Volhard, and H. Klüding. 1984. Mutations affecting the pattern of the larval cuticle in Drosophila melanogaster. II. Zygotic loci on the third chromosome. Wilhelm Roux's Arch. 193: 283-295.

Lawrence, P.A., P. Johnston, P. Macdonald, and G. Struhl. 1987. Borders of parasegments in Drosophila embryos are delimited by the fushi tarazu and even-skipped genes. Nature 328: 440-442.

Martinez-Arias, A. and P.A. Lawrence. 1985. Parasegments and compartments in the Drosophila embryo. Nature 313: 639642.

Nüsslein-Volhard, C. and E. Wieschaus. 1980. Mutations affecting segment number and polarity in Drosophila. Nature 287: $795-801$.

Nüsslein-Volhard, C., E. Wieschaus, and H. Klüding. 1984. Mutations affecting the pattern of the larval cuticle in Drosophila melanogaster. I. Zygotic loci on the second chromosome. Wilhelm Roux's Arch. 193: 267-282.

Rosenberg, U.B., C. Schröder, A. Preiss, A. Kienlin, S. Cotë, J. Riede, and H. Jäckle. 1986. Structural homology of the product of the Drosophila Krüppel gene with Xenopus transcription factor IIIA. Nature 319: 336-339.

Scott, M.P. and S.B. Carroll. 1987. The segmentation and homeotic gene network in early Drosophila development. Cell 51: $689-698$.

Tautz, D., R. Lehmann, H. Schnüsch, R. Schuh, E. Seifert, A. Keuhn, K. Jones, and H. Jäckle. 1987. Finger protein of novel structure encoded by hunchback, a second member of the gap class of Drosophila segmentation genes. Nature 327: 383-389.

Wieschaus, E., C. Nüsslein-Volhard, and G. Jürgens. 1984. Mutations affecting the pattern of the larval cuticle in Drosophila melanogaster. III. Zygotic loci on the X chromosome and fourth chromosome. Wilhelm Roux's Arch. 193: 296307. 


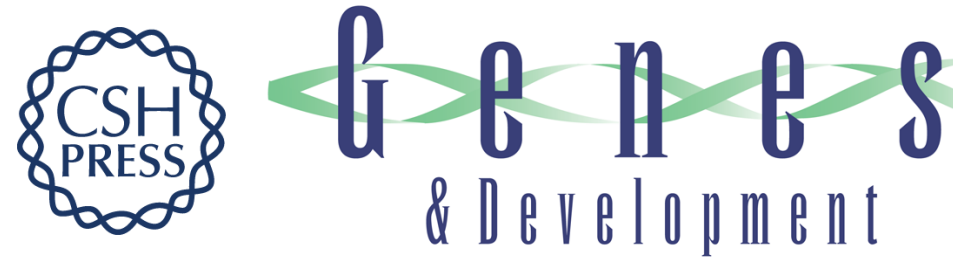

\section{Expression, function, and regulation of the hairy segmentation protein in the Drosophila embryo.}

S B Carroll, A Laughon and B S Thalley

Genes Dev. 1988, 2:

Access the most recent version at doi:10.1101/gad.2.7.883

References This article cites 24 articles, 3 of which can be accessed free at: http://genesdev.cshlp.org/content/2/7/883.full.html\#ref-list-1

License

Email Alerting

Service

Receive free email alerts when new articles cite this article - sign up in the box at the top right corner of the article or click here.

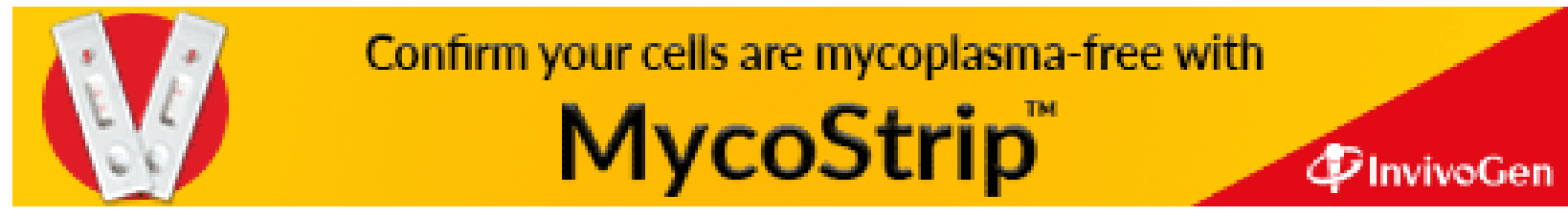

